Yayınlayan: Ankara Üniversitesi KASAUM

Adres: Kadın Sorunları Araştırma ve Uygulama Merkezi, Cebeci 06590 Ankara

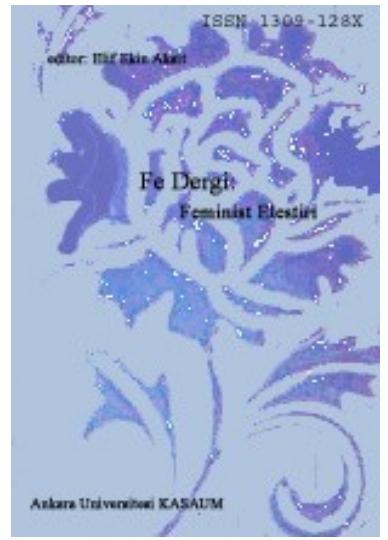

Fe Dergi: Feminist Eleştiri Cilt 2 Sayı 1

Erişim bilgileri, makale sunumu ve ayrıntılar için:

http://cins.ankara.edu.tr/

Tarihi Yeniden Kuranlar Üzerine Deneme

Ali Saltan

Çevrimiçi yayına başlama tarihi: 5 Haziran 2010

Bu makaleyi alıntılamak için: Ali Saltan, “Tarihi Yeniden Kuranlar Üzerine Deneme,” Fe Dergi 2, no. 1 (2010): 1-5.

URL: http://cins.ankara.edu.tr/saltan.html

$\mathrm{Bu}$ eser akademik faaliyetlerde ve referans verilerek kullanılabilir. Hiçbir şekilde izin alınmaksızın çoğaltılamaz. 


\section{Tarihi Yeniden Kuranlar Üzerine Deneme}

\section{Ali Saltan ${ }^{*}$}

Bu çalışmadaki fotoğraflar Diyarbakır'da gerçekleştirilen, kadınlara ve gençlere yönelik istihdam projeleri çerçevesinde üretilmişlerdir. Mermer atıklarından mozaik üreterek hayatlarını yeniden dönüştürmeye çalışan kadınların görselleri bu deneme kapsamında fotoğrafçının deneyimleri ve yorumlarlyla sunulmaktadır.

Zeynep'le Sur'un hemen dibinde kurulan pazarın içinde buluşuyoruz. Hızlı adımlarla pazar kalabalığından çıkıp dar sokaklara sapıyoruz. Neredeyse hiç konuşmuyoruz yürürken. İkimiz de konuşmaya nereden başlayacağımızı bilemeden adımlarımızı sayıyoruz. Eve yaklaştığımızda sessizlik bozuluyor.

-Evimiz biraz uygun değil, kusura bakma!

Evin kapısını kardeşi aralıyor. İçeri giriyoruz. Soldaki odada bir yaşlı kadın oturuyor. Bizi görünce ayaklanıyor. Yanına gidiyoruz.

Televizyonda Kürtçe haber ajansları dönüyor. Zeynep'in annesi Türkçe neredeyse hiç bilmiyor. Hayır, hiçbir vakit Türkçe konuşmak istememiş.

Sessizlik çöküyor üzerimize. Anne, yüzünü bana dönüp kendi dilinde bir şeyler anlatıyor. Kelimelere anlam veremesem de yüzünü yaralayan zamanın hüzünlü kabuğu çok şeyler anlatıyor bana.

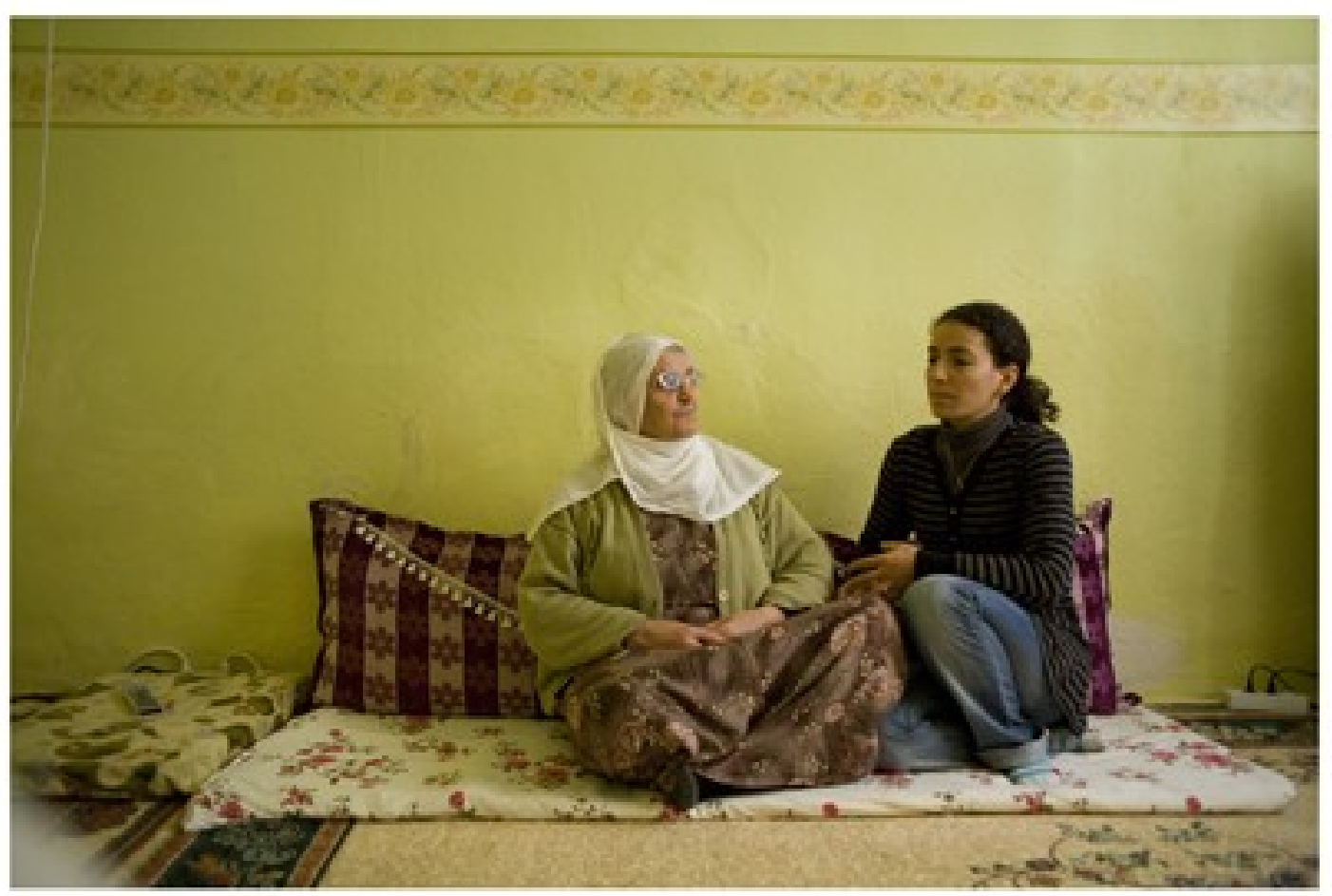

'Hiçbir tarih dilsiz değildir. İstedikleri kadar sahiplensinler, bozsunlar, hakkında yalan söylesinler, insan tarihi çenesini kapalı tutmayı reddeder. Sağırlığa ve cehalete rağmen, geçmiş zaman şimdiki zamanın içinde tiktaklamayı sürdürür.'

Dört Ayaklı Minare'nin oradan sağa dönüyorsun. Upuzun bir sokak karşılıyor seni. İlerliyorsun, solunda hamam. Yıkılmış, bacasında otlar.

\footnotetext{
*Ankara Üniversitesi, Kadın Çalıșmaları.
} 
Az ileride demir kapının ara kalmış yeşilliği içine çekiyor seni. Dalıyorsun. Bir halayın içinde buluyorsun kendini. Sarıyor her yanını. Orta yerde, kadınların upuzun parmakları arasında küçülüyor taşlar. Ağacın gövdesine yaslanmış, elinde bendir, ezgiler çığırıyor bir kadın. Ona yeniden ses veren kadınları kutluyor. Ardımda, sesin renkleri vardır diyor Rojda. Bizim buralarda sesimiz sarıdan kırmızıya doğru eğimlidir...

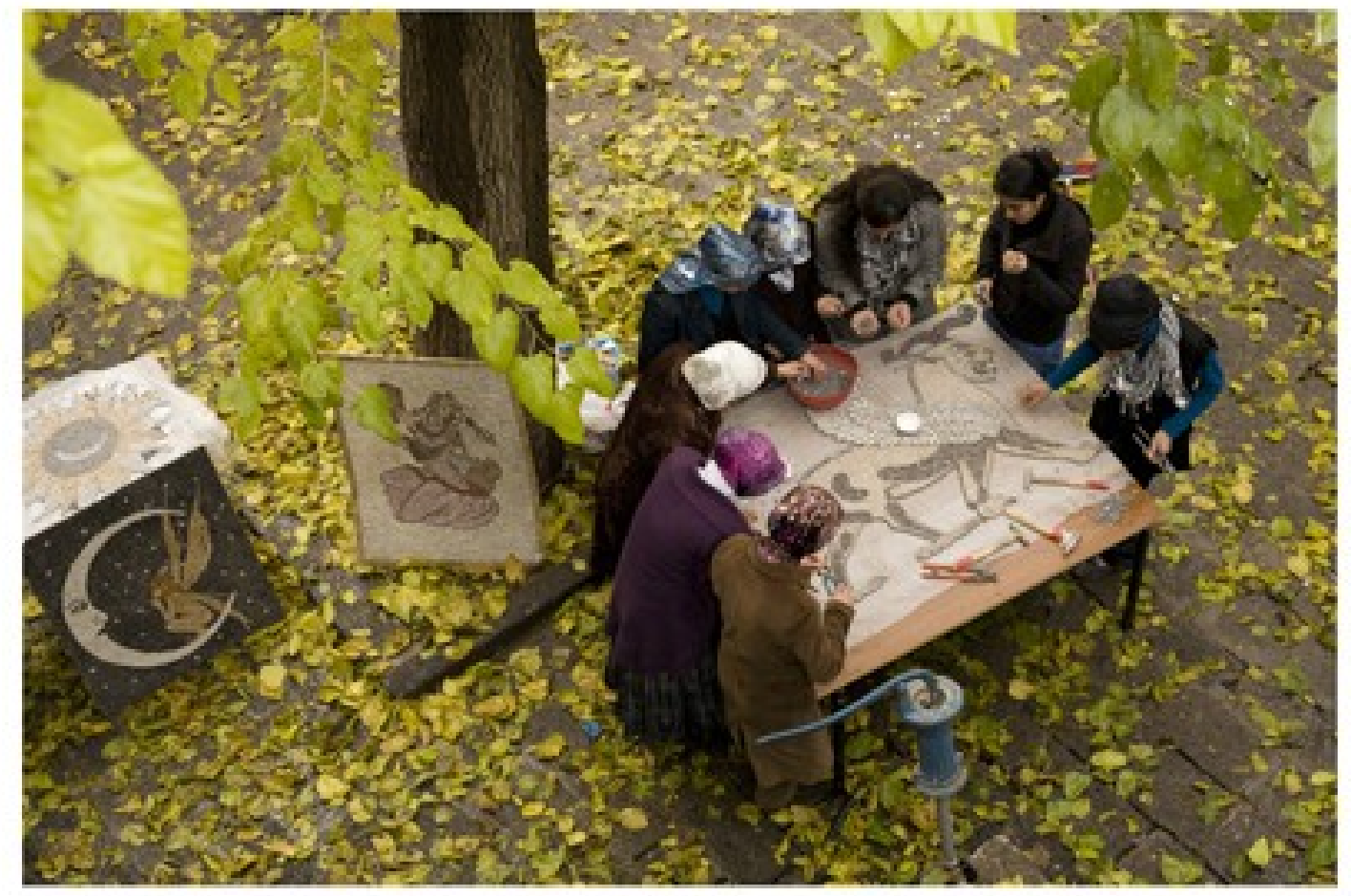

'Sadece güçlüler için tarih dikine bir çizgidir ve bugünleri daima o çizginin zirvesindedir. Aşağıdakiler için tarih ancak geriye ve ileriye bakarak cevaplanabilecek bir sorudur, bu da yeni sorular yaratır.' Marcos

Kendi yaşamlarının 'yıkıntıları' arasında sıkışmış 60 kadın. Onlar yıkıntıların arasında yeniden kendi hikayelerini yazmaya çalışıyorlar.

Kaybedilmiş, unutturulmuş tarihin silik nesnelerinde, artıklarında öyküleri derliyorlar. O öykülerden kendi öykülerine bir yol arıyorlar.

"Taş elimde can buluyor, ona hayat veriyorum" diyor Sıdıka.
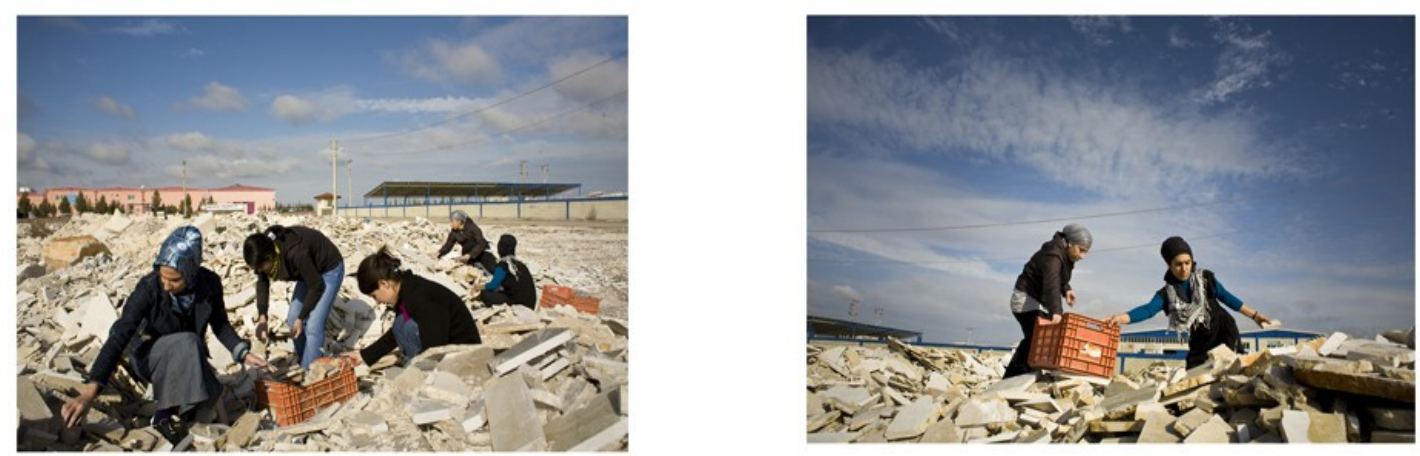


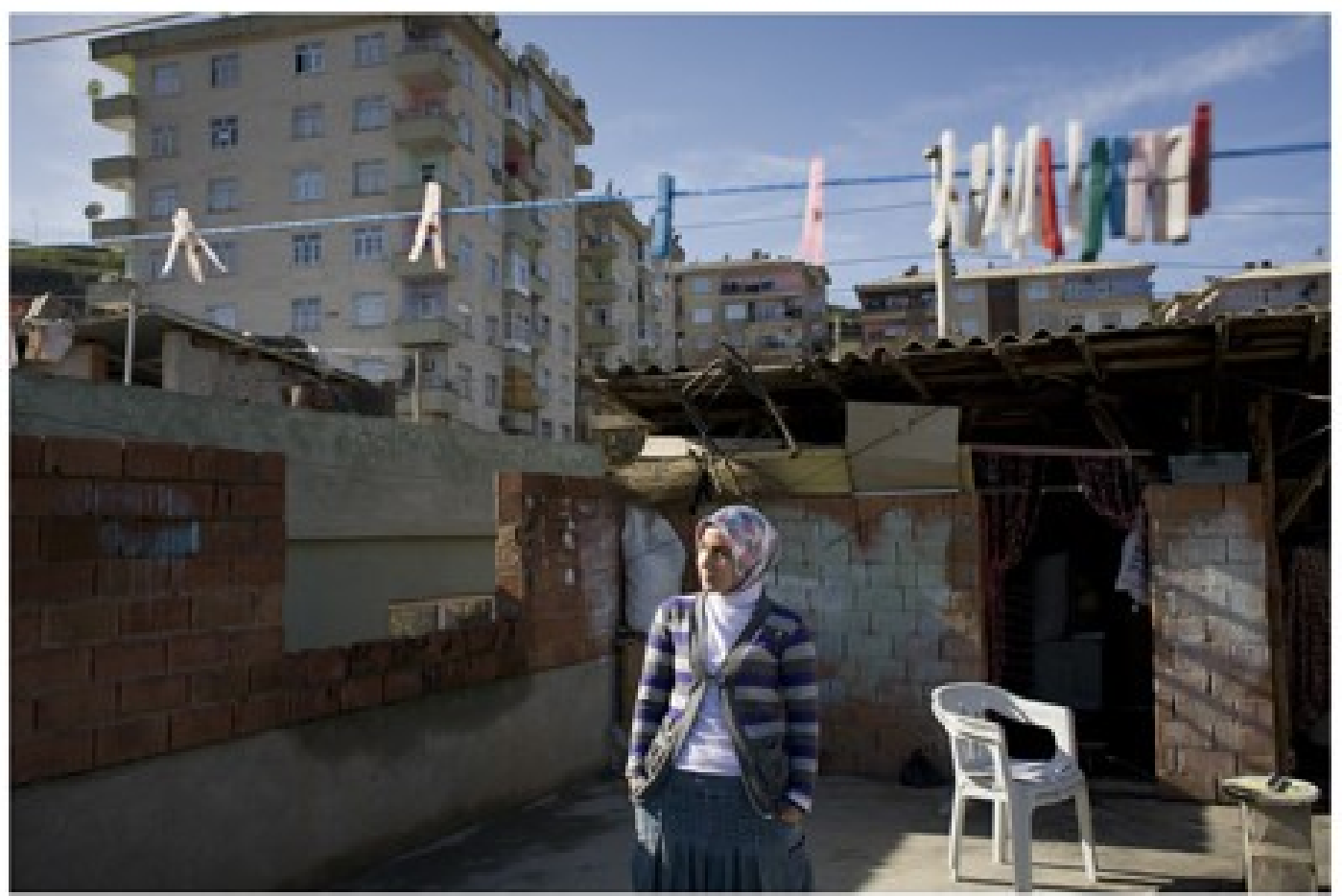

'Tarihçiler geçmişten bir hazine, bir miras olarak söz ederler. Tarihin ezilen sınıfları içinse tarih bir enkaz, bir yıkıntılar yığını, bir talan alanıdır. Bir dizi öykünün birbirini doğurarak bugüne doğru ilerlediği bir birikim değil, geçmişin bugüne kavuşması değil, bir öykünün başka öyküleri tüketerek, unutturup yok ederek kendini tek kılması, geçmişin beklentilerinin yok edilmesidir. Bu yüzden kültür denen sürekliliğin ardında hep bir barbarlık vardir.'2

Amed. Küçük mermer taşlarını parmakları arasında dolandırıyor. Karşısında öylece duruyorum.

-Beni sizin eve götürsene Amed.

-Olur

Amed ve kuzeni Sultan'la evlerine gitmek üzere atölyeden çıkıyoruz. Evin avlusunun kapısından içeri kafamı uzatıyorum. İçeride, yüzlerini güneşe vermiş duruyor kadınlar. Amed ve Sultan'ın anneleri, ninelere, komşuları...Az biraz soluk alıyoruz. Duvarın dibinde duran yaşlı kadın, fotoğraf makinesini görünce kendi dilinde bir şeyler söyleyerek elini göğü tutacakmışçasına yukarı doğru uzatıyor. Havalanan bir kuşun kanadına birakıyor umutlarını, acılarını... 


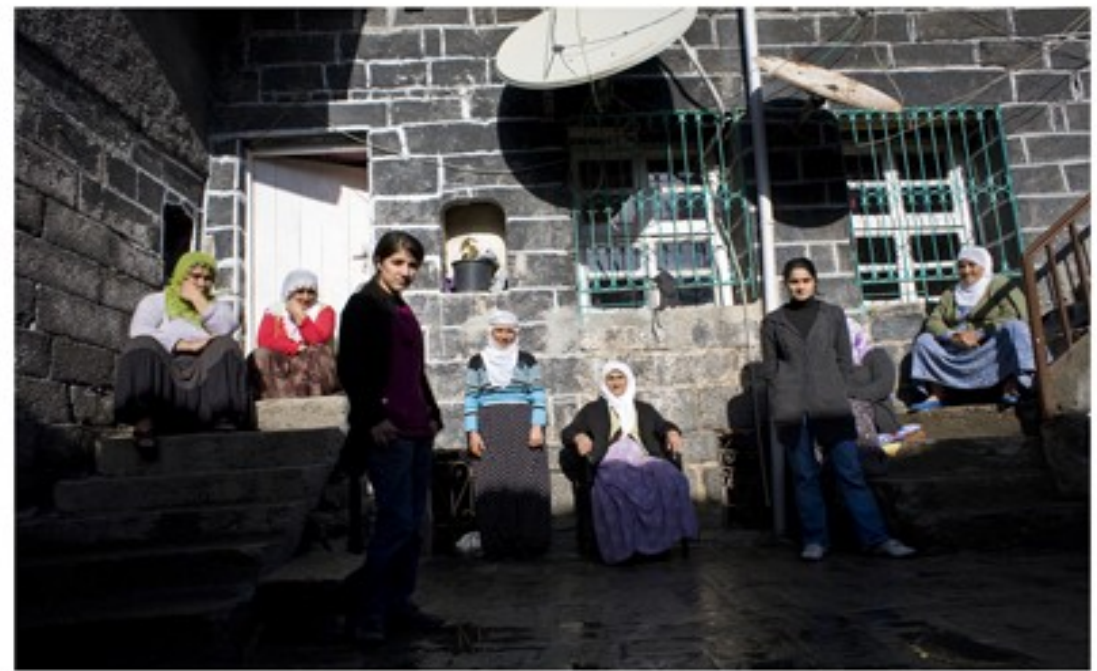

'Yerinden yurdundan edilmiş ve kaçak...

Onlarla aramızda ortak olan ne? Korku dolu ifadeleri içimdeki sönmeye yüz tutmuş derin ve unutulması zor acıları tekrar uyandırıyor. Acılı hafızamda, başka bir diyarın, felakete uğramış insanların bir sel gibi önümüzde aktığı geceler canlanıyor. Birbirine düşman halklar bir felaketle karşılaştıklarında birbirlerine ne kadar benzediklerin, aynı ruhu paylaşıp aynı çı̆̆lıkları attıklarını, aynı lanetleri ve aynı dilekleri birbirinin aynı vurgularla dile getirdiklerini bilselerdi...’3

\section{KAYNAKÇA}

John Berger, $A$ 'dan X'e (İstanbul: Metis Yayınları, 2008).

Nurdan Gürbilek Sunuş, Son Bakışta Aşk, W. Benjamin (İstanbul: Metis Yayınları, 2001).

Zabel Yesayan Yeter!, Bir Adalet Feryad,, Beş Ermeni Feminist Yazar, haz. L.Ekmekçioğlu, M. Bilal (İstanbul: Aras Yayınları, 2006).

Subcomandande Marcos 
'Galeano'dan aktaran John Berger, A'dan X'e (İstanbul: Metis Yayınları, 2008), 87.

${ }^{2}$ Nurdan Gürbilek Sunuş, Son Bakışta Aşk, W. Benjamin (İstanbul: Metis Yayınları, 2001), 34

${ }^{3}$ Zabel Yesayan Yeter!, Bir Adalet Feryad,, Beş Ermeni Feminist Yazar, haz. L.Ekmekçioğlu, M. Bilal (İstanbul: Aras Yayınları, 2006), 328. 